\title{
Emotionality in a second language: It's a matter of time
}

\author{
Bertram Opitz $^{\mathrm{a}, *}$, Juliane Degner ${ }^{\mathrm{b}}$ \\ ${ }^{a}$ Experimental Neuropsychology Unit, Saarland University, Germany \\ ${ }^{b}$ Department of Social Psychology, University of Hamburg, Germany
}

\begin{abstract}
The present study investigated the well acknowledged phenomenon of a different sense of emotionality in a person's first (L1) and second language (L2). Event-related potentials were recorded during the reading of pleasant, unpleasant and neutral words in L1 and L2. Enhanced processing of both emotional compared to neutral words was reflected in an amplified early posterior negativity (EPN) about 280 - $430 \mathrm{~ms}$ after word onset. While the EPN did not differ in amplitude between L1 and L2, it was delayed for L2. Interestingly, a better task performance in L2 but not L1 predicted longer delays of the EPN. These results might indicate that the affective valence of L2 words is processed in a less immediate way due to delayed lexical access. This is interpreted in terms of interference in a highly integrated L1/L2 mental lexicon.
\end{abstract}

Keywords: emotion, second language, ERP, early posterior negativity

${ }^{*}$ Corresponding author 


\section{Introduction}

Being bilingual is typically seen as a big advantage in todays rapidly diversifying world. Knowing a second language gives the opportunity to understand and converse with people of different countries or cultures with whom efficient communication would otherwise be very difficult. However, having learned a second language (L2) later than one's first language (L1) is often related to the persistent subjective impression that the second language does not reach the same quality as one's native language, even with highest levels of proficiency. For example, sequential bilinguals, i.e. individuals that acquired their L2 after their L1, frequently report that they experience their second language to be less emotional as compared to their native language and that although they perfectly know the emotional meaning of words in L2, they do not sense it as with words in L1 (e.g., Pavlenko, 2005). If you are a native speaker of German hearing your child or partner say "Ich liebe Dich." would arouse a higher degree of happiness than its translation equivalent "I love you.", even if you are fluent in English. Similarly, swear words or taboo words leave you relatively untouched - even if you perfectly understand their meaning. Findings in linguistic research using introspection, interviews, or literary analysis corroborate these subjective impressions. For example, bilinguals rate the emotional force of swear words and taboo words as weaker in L2 than L1 (Dewaele, 2004) or feel less inhibited talking about embarrassing topics when using L2 as compared to L1 (Bond \& Lai, 1986). Note that such experiences are frequently reported even by highly proficient bilinguals, not just 
beginning learners or poor speakers of a second language (see Pavlenko, 2005). Thus although being potentially able to fluently converse in a second language, bilinguals' ability to grasp the emotional connotations of words and phrases might be seriously impaired, and thus hinder efficient and smooth communication - especially in emotional contexts.

In addition to subjective measures previous research also investigated the physiological arousal mostly by means of skin conductance responses (SCR, see Harris, et al., 2006, for review). These studies demonstrated consistently that for late sequential bilinguals the SCR is weaker for taboo words, insults (e.g., "You suck!"), or reprimands (e.g., "Shut up!") in L2 as compared to L1 (Harris et al., 2003; Harris, 2004). Such psychophysiological data substantiate the subjective experience of a different sense of emotionality in L1 and L2. Moreover, they allow to identify various factors of the language-learning process that might have consistent effects across many individuals. For example, age of L2 acquisition seems to influence the response of the autonomic nervous system to affective words. In this line, Harris (2004) demonstrated comparable SCR for L1 and L2 taboo words and reprimands for early and, therefore, near native bilinguals corroborating the participants equal subjective ratings of unpleasantness.

The origin of these differences between L1 and L2 has been attributed to the special features of emotional words, i.e. valence and arousal, that differentiates them from nonemotional words in the mental lexicon. The access of this additional information represented in the mental lexicon is assumed to be reflected in slower processing times for 
emotional as compared to nonemotional words (Pavlenko, 2008). It has been further argued that "emotion concepts vary across languages and that bilinguals' concepts may, in some cases, be distinct from those of monolingual speakers" (Pavlenko, 2008, p. 147). Thus, it is conceivable that emotional words are processed more slowly in L2 as compared to L1. Support for this view is provided by studies demonstrating slower reaction times for instance in an affective priming paradigm (Altarriba \& Canary, 2004; Degner et al., 2012). For instance in the study by Altarriba \& Canary (2004) English monolingual and Spanish-English bilingual participants performed lexical decisions to English words in emotionally related or unrelated conditions. Positive priming effects in related conditions were found for both groups of participants with longer latencies for bilinguals than for monolinguals.

The difference in mental representations of emotional words in L1 and L2 is best explained through differences in the timing and/or context of language acquisition, assuming that the later and more formal acquisition of a second language (e.g., in school settings) does not allow for the establishment of emotionally relevant autobiographical and other diverse sets of associations in relation to emotional interpersonal interactions (e.g., Altarriba, 2003; Harris et al., 2006) as the natural and early acquisition of L1. This so-called 'emotional contexts of learning' theory holds that a word's distinctive emotional feel is learned across multiple exposures of a word in distinctive emotional contexts (Harris et al., 2006). Consequently, the reduced emotionality of L2 as compared to L1 could 
then be attributed to weaker associations between a word and its emotional context. Such weak associations have two possible sources of origin: too few encounters of the word per se, as it might be the case for low proficient bilinguals, and/or an insufficient emotionality of the context independent of the learner's proficiency. Although these accounts contain sufficient explanations of the possible origins of reduced emotionality of L2 as compared to L1, they do not offer any insights into the possible difference in native and second language processing underlying this phenomenon. The current research aimed at filling this gap using neurophysiological measures.

To study language processing within the field of cognitive neuroscience, event-related potentials (ERP) have proven to be an effective and frequently used method. The effects of emotional content on word processing have been extensively investigated in L1 (Herbert, Junghöfer \& Kissler, 2008; Kissler, Herbert, Peyk \& Junghöfer, 2007; Schacht \& Sommer, 2009a; Scott, O’Donnell, Leuthold \& Sereno, 2009). Using well-controlled verbal stimulus material these studies consistently report an early (around 200 to 320ms) enhanced negativity for positive and negative emotionally arousing words compared to neutral words that occurs predominantly at left temporo-occipital electrode sites. This so-called early posterior negativity effect (EPN) has been demonstrated to be independent of the word class, thus for nouns, verbs and adjectives that were matched for a number of other potentially relevant dimensions such as word length, word frequency or concreteness (Herbert et al., 2008; Kissler et al., 2009; Schacht \& Sommer, 2009a). The EPN is 
elicited at various presentation rates (Herbert et al., 2008; Kissler et al., 2007) and seems independent of the actual task requirements, as it was found using silent reading and nonemotional grammatical decision tasks (e.g., Kissler et al., 2007, 2009) as well as lexical decision tasks (Schacht \& Sommer, 2009a; Scott et al., 2009). Thus, the EPN effect provides a very robust and replicable phenomenon of the processing of emotional words.

It has been suggested that the EPN reflects the spontaneous activation of a word's emotional connotation immediately after the visual word-form representation has been accessed (Kissler et al., 2007, 2009). This view holds that bidirectional connections between the midfusiform gyrus in the extrastriate ventral stream and the amygdala activated directly after the lexical access may enhance the brain's response to emotional words. Such an interaction between extrastriate areas and the amygdala has indeed been demonstrated in emotional face processing (Vuilleumier et al., 2004) and it has been argued that this leads to a prioritized visual processing of emotionally significant stimuli due to a rapid capture of attention (Lang et al., 1997). A comparable attentional modulation of the EPN has been previously demonstrated in studies showing that attended stimuli were associated with larger EPNs (e.g., Schupp et al., 2007a,b).

If the subjective reduction of emotionality in L2 is indeed based on differential processing of L2 as compared to L1, this framework offers two possible processing differences. On the one hand, the emotional content of a word may be activated to a lesser extent in L2 as compared to L1. As a consequence we would expect the EPN elicited by 
emotional valent words in L2 to be reduced in amplitude as compared to L1. On the other hand, as outlined above the lexical access may be delayed in L2, delaying the subsequent enhancement of the EPN by the word's emotional connotation. This should result in a delayed peak latency of the EPN rather than in a reduction of its amplitude. However, both effects could also occur together resulting in an attenuated and delayed EPN in L2.

\section{Materials and methods}

\subsection{Participants}

Thirty-three self-identified bilinguals were recruited at Saarland University to take part in the study. Thereof 17 were German-French bilinguals and 16 were French-German bilinguals. One German-French bilingual participant was excluded from all analyses because of excessive eye blink artifacts. The remaining 32 participants ( 8 male) were at the time of study between 18 and 28 years old. They all had normal or corrected-to-normal vision and were without history of neurological or psychiatric disorder. All participants signed informed consent before the experiment and were paid $€ 7.5$ per hour for participation.

The mean age at which participants started learning their respective second language was 12 years (ranging between 7 and 16), and all had spent at least one stay longer than 6 months $(\mathrm{M}=14.9$ months, ranging from 6.5 to 60$)$ in a country in which they actively spoke their L2. The mean self-rated frequency of daily L2 use in the last three months was 
3.59 (ranging between 1.33 and 5 with a maximal score of 7 , see procedure section for details of the questionnaire used to asses the individual frequency of daily L2 use). The self-rated proficiency in their respective L2 of 68.9 on a 100-point scale was well above average (50 points, $\left.t_{31}=6.13, p<.001\right)$. According to these self-reports all participants can be regarded as sequential and unbalanced bilinguals with proficient knowledge of L2.

\subsection{Stimuli}

Stimuli were frequently used nouns, likely to be known by moderate (non-native) speakers of either language (as confirmed by post-tests, see below) that were selected from a larger database according to valence and arousal ratings obtained from monolingual speakers of German and French (cf., Degner et al., 2012). These ratings were collected using a computerized version of the Self-Assessment Manikin (SAM: Bradley \& Lang, 1994). From this pool, 300 French-German synonym pairs were selected such that they matched according to word length, valence, and frequency of use (based on the databases LEXIQUE, New et al., 2004, and CELEX, Baayen et al., 1995 for French and German words, respectively). Crucially, these synonyms did not include cognates and inter-lingual homographs, because such words have been shown to foster bilingual lexical processing (e.g., Costa et al., 2000). These words varied in their emotional valence, with 100 words being negative (e.g., Cauchemar - Alptraum - nightmare), 100 neutral (e.g. Feuille - Blatt - leaf) and 100 positive (e.g., Blague - Witz - joke). All pleasant and 
unpleasant words were matched for perceived arousal but differed from neutral words. Furthermore, pleasant, neutral, and unpleasant words differed significantly in valence ratings (see Table 1 for further details). For each language 30 additional orthographically legal pseudo-words were created by exchanging two letters from existing words across all three valence groups. A complete list of the stimulus material is provided as supplemental material. The 330 German-French word pairs were divided into two lists of 165 words, including 15 pseudo-words contained in both lists.

— Table 1 about here -

A critical issue when investigating emotional language regards possible differences in the set of stimuli. Thus, words chosen for one language could have been inherently more emotionally arousing than analogous items selected for the other language. Consequently, differences between L1 and L2 could be attributed to differences in items rather than status of the language as being acquired as first or second. Even after equating items according to L1 ratings of emotionality, this matching could be imperfect, because individuals from different cultures may respond differently to the same rating scales. To circumvent this problematic issue, we employed a balanced bilingual design in the cur- 
rent study (cf. Anooshian \& Hertel, 1994; Degner et al., 2012). In such design, one and the same language (e.g. German) is the L1 for the group of German participants but the L2 for the French participants and vice versa for the other language (i.e. French). Hence, possible effects of differences in emotionality between L1 and L2 are controlled for.

\subsection{Procedure}

The experiment was controlled by E-Prime software (Psychology Software Tools) and involved two runs of five differently randomized presentations of a list of 165 stimuli, one language per run. The lists were selected in a way that the German list did not contain any translation of the French list. The order of the French and German list was counterbalanced across the participants' native language. That means that half of the German and French native participants started with their respective L1 list, while the other half started with the L2 list.

The stimuli were presented in black (18 pt Lucida Console font) in the center of a white 17 inch PC-monitor background with a stimulus-duration of $1000 \mathrm{~ms}$. A fixation cross was presented during the inter-stimulus interval of $200 \mathrm{~ms}$. Participants performed a lexical monitoring task (LMT), that can be seen as a variant to the commonly used lexical decision task. They were instructed to press the space bar as fast and accurate as possible upon the occurrence of a pseudo-word that is orthographically similar to real words in the respective target language. No button press was required for words. This task was chosen to maintain a high attention level throughout the experiment. All instructions were given 
in written form in the participants' native language.

In addition, a questionnaire was administered that assessed participants' age and context of L2 acquisition as well as self-ratings of L2 proficiency and use. Participants rated their L2 proficiency referring to different aspects of language use (vocabulary, accent, comprehension, writing, and reading abilities) using a 100mm long line as a scale with the left anchor corresponding to zero ("non") and the right anchor representing 100 (or "native-like"). The five aspects were highly correlated (Cronbachs alpha $=.83$ ) and thus combined into a single variable further referred to as self-rated L2 proficiency. In addition, self-ratings of frequency of L2 use in daily life on a seven-point scale $(1=$ not at all, 7 = exclusively) were obtained (see Degner et al., 2012, for details). The entire experimental session lasted approximately 1.5 hours with about 30 minutes devoted to the questionnaire.

\subsection{EEG recordings and analysis:}

Participants were comfortably seated in a dimly lit, electrically shielded and soundattenuated chamber. Electroencephalograms (EEG) were continuously recorded from 59 $\mathrm{Ag} / \mathrm{AgCl}$ scalp electrodes embedded in an elastic cap (EASYCAP GmbH) according to the extended 10/20 system (Sharbrough, Chatrian, Lesser, Lüders, Nuwer \& Picton, 1991) and from the right mastoid. The EEG from all sites was recorded with reference to the left mastoid electrode and recalculated off-line to $\mathrm{Cz}$ reference. The ground electrode was placed on the forehead. Vertical and horizontal electrooculograms were recorded with 
additional electrodes located above and below the right eye and outside the outer canthi of both eyes. Inter electrode impedances were kept below $10 \mathrm{k} \Omega$. All channels were amplified with a band-pass from DC to $70 \mathrm{~Hz}$ and A/D converted with 16 bit resolution at a rate of $500 \mathrm{~Hz}$. Off-line data processing included a digital band-pass filter from 0.5 to 30 $\mathrm{Hz}(-3 \mathrm{~dB}$ cutoff). An automatic rejection criterion (voltage variation of more than $30 \mu \mathrm{V}$ within a 200 ms sliding time interval) was applied to the EOG channels to mark segments contaminated by eye movement artifacts. These recording epochs were corrected using a linear regression approach (Gratton, Coles \& Donchin, 1983). Furthermore, all channels were scanned manually for additional disturbances.

Artifact-free epochs ranging from -200 to $800 \mathrm{~ms}$ with respect to the stimulus onset were averaged separately for each participant, stimulus type (i.e., positive, neutral, and negative words) and language (L1 vs. L2), with the $200 \mathrm{~ms}$ prior to word onset serving as the baseline. These ERPs included all artefact-free trials irrespective of accuracy to compare the present results with the results of previous studies averaging across all stimuli (cf., Herbert et al., 2008; Kissler et al., 2007, 2009). Moreover, this ensured an equal signal-to-noise ratio across stimulus types and language. As the EPN was consistently enhanced over the left hemisphere its amplitude was quantified at left posterior electrodes (O1, P3, P5, P7, PO3, and PO7) as mean voltages in three consecutive 50 ms time intervals starting from $280 \mathrm{~ms}$ post stimulus onset. The peak latency was measured from stimulus onset to the most negative peak in the 280 to $430 \mathrm{~ms}$ time interval in the difference wave 
between emotionally valent words and neutral words. The amplitude data were subjected to an ANOVA with the repeated-measure factors stimulus type (i.e., positive, neutral, and negative words), language (L1 vs. L2), and time window (i.e., early, middle, and late) and the between subject factor native language (German vs. French). The GreenhouseGeisser adjustment for nonsphericity was used whenever appropriate and the corrected $\mathrm{p}$ values are reported together with the uncorrected degrees of freedom.

\section{Results}

Results of the LMT revealed that participants identified on average $93 \%$ of the pseudowords in their native language and $70 \%$ in their respective L2 (see Table 2). An ANOVA contrasting this difference between L1 and L2 for German and French participants revealed a significant main effect of language (L1 vs. L2, $F_{1,30}=57.05, p<.001, \eta_{p}^{2}=$ $.655)^{1}$. This indicates that the detection of pseudo-words in L2 was significantly below the performance in L1. Neither the main effect native language nor the interaction involving this factor reached significance, suggesting that German and French participants performed the LMT equally. As none of the participants committed more than ten per cent false positive responses to real words these responses were not analyzed.

\footnotetext{
${ }^{1}$ Due to equipment malfunction behavioral data of one German participant was lost. This Participant was therefore excluded from the analysis of the behavioral data
} 
As can be inferred from Figure 1, word valence affected the ERP in the interval from 280 to $430 \mathrm{~ms}$ after word presentation. Positive and negative words elicited a more negative-going deflection at temporo-occipital recording sites as compared to neutral words. This was confirmed by an ANOVA contrasting the ERPs elicited by positive, neutral, and negative words in the three time windows for L1 and L2 processing in both groups of German and French native speakers. This analysis revealed a marginally significant main effect of word valence $\left(F_{2,60}=2.98, p<.08, \eta_{p}^{2}=.090\right)$ that was qualified by a significant valence by time window interaction $\left(F_{4,120}=3.19, p<.05, \eta_{p}^{2}=.096\right)$ and a triple interaction valence by time window by language $\left(F_{4,120}=3.01, p<.05, \eta_{p}^{2}=\right.$ .091). Planned comparisons revealed that the EPN to neutral words differed from the mean of the EPN to positive and negative words $\left(F_{1,30}=4.09, p<.05, \eta_{p}^{2}=.120\right)$ whereas no difference between positive and negative words could be obtained $\left(F_{1,30} \ll\right.$ $\left.1, \eta_{p}^{2}=.001\right)$. Consequently, all further analyses were carried out on the difference wave between the ERPs to emotionally valent words (collapsed across both valences) and neutral words. Moreover, neither the main effect of native language nor any interaction involving this factor reached significance. For this reason the between group factor native language was not considered in further analysis. Analysis of the effect of 
language (L1 vs L2 processing) revealed no overall differences between L1 and L2 processing $\left(F_{1,31} \ll 1, \eta_{p}^{2}=.005\right)$ but a significant language by time window interaction $\left(F_{2,62}=6.38, p<.005, \eta_{p}^{2}=.171\right)$. This indicates that the EPN was elicited by L1 and L2 words in a similar manner, but the timing of the EPN differed across L1 and L2. Tested separately for each time window, a significant language effect was observed for the first time window $\left(F_{1,31}=4.86, p<.05, \eta_{p}^{2}=.136\right)$, suggesting that emotional processing of L2 words was delayed relative to the processing of L1 words. To provide further support for this finding we also analyzed the peak latency of the difference wave between emotionally valent words and neutral words. This analysis revealed a significantly delayed EPN to L2 words (L1 words: $302 \mathrm{~ms}$, L2 words: $321 \mathrm{~ms} ; F_{1,31}=9.06, p<.005, \eta_{p}^{2}=.226$ ).

— Figure 1 about here —

In a next step we investigated whether individual differences in the delay of the EPN, operationally defined as the peak latency of the EPN in L2 minus L1, was related to task performance, age of acquisition, L2-proficiency, or frequency of L2-use. In a first step, a correlation analysis (see Table 3 for complete results) revealed a significant relationship between the delay of the EPN and the self-reported proficiency $(r=$ $.31, p<.05$ ) and L2 task performance (i.e., the proportion of hits to the pseudowords 
in the L2 LMT, $r=.57, p<.001)$. In addition, there was also a positive correlation of the self-reported proficiency with $\mathrm{L} 2$ task performance $(r=.53, p<.001)$ indicating that performance in the LMT reflects L2 proficiency to some degree. To show that this relationship between the EPN delay and measures of proficiency persists when other factors which were shown to be relevant for the acquisition of L2 are considered; a stepwise regression analysis was conducted including age of L2-acquisition and frequency of use as additional regressors. Furthermore, to control for general performance in the LMT the accuracy in the L1 LMT was included in this analysis. In the resulting model only task performance was associated with a significant regression weight $\left(F_{1,29}=13.71, p<.001, R^{2}=.321 ; \beta_{\text {accuracy in the } L 2 L M T}=.566\right.$, see Table 4 for complete results), indicating that better task performance in L2 - thus more efficient lexical access in L2 but not L1 - predicted a later peak latency of the EPN in L2.

— Table 3 about here -

— Table 4 about here - 


\section{Discussion}

The purpose of the current experiment was to investigate the early time course of emotion word processing in first and second language. Positive, negative, and neutral words were presented randomly in a LMT while brain electrophysiological responses were recorded. We found the EPN to be consistently enhanced to emotionally valent (positive and negative) as compared to neutral words, replicating previous results of native language research (Herbert et al., 2008; Kissler et al., 2009; Scott et al., 2009). Importantly, this valence effect showed a bilateral occipito-temporal negativity, which is the typical scalp distribution of the EPN (e.g., Schupp et al., 2003). However, the EPN emotion effect in the present study was observed slightly later than emotion effects recently reported by others (Herbert et al., 2008; Kissler et al., 2007).

This discrepancy might be attributed to differences in task requirements as previous studies often used a passive reading task (e.g., Kissler et al., 2007) while the present study employed a LMT. This is in line with previous reports demonstrating modulations of emotion effects by varying task requirements (Bayer et al., 2010; Schupp et al., 2007a; Schacht \& Sommer, 2009a,b). For instance, Schacht and Sommer 2009a using a lexical decision task reported an EPN in the same time range as it was observed in the present study. It has been previously argued that the degree of linguistic processing modulates the direction of attention to the affective content during word processing reflected in the EPN (Hinojosa et al., 2010; Kissler et al., 2007; Schacht \& Sommer, 2009b). Thus, it could be argued that 
only minimal linguistic processing as in passive reading tasks will lead to faster lexical access as compared to elaborate lexical-semantic processing required in previous studies using a similar task (Palazova et al., 2011; Schacht \& Sommer, 2009a,b). Consequently, the EPN latency will be longer when more elaborate and effortful linguistic processing is required. Tentative support for this notion was recently provided by the observation of a shortened EPN latency in a semantically primed as compared to an unprimed lexical decision task (Schacht \& Sommer, 2009b). In two experiments participants were required to make word/nonword decisions on emotional verbs (e.g., to kiss or to kill) with the only difference between experiments being the semantic context provided ba a single preceding noun (e.g., lover - kiss) in one of the experiments. The observed acceleration of the early emotion process reflected in the EPN when a semantic context was provided by a prime was explained with a valence-unspecific semantic priming.

As an alternative, it is also possible that in an effort to equate German and French words regarding their word frequency, valence and arousal ratings the words in the present study were less typical, resulting in a longer identification. Nevertheless, the present results are in good agreement with the notion of motivated attention predicting preferential visual processing of emotionally arousing words as a result of a rapid capture of attention (Herbert et al., 2008; Lang et al., 1997). This early facilitated processing of emotional words has been attributed to the activation of bidirectional connections between the visual word-form area in the extrastriate ventral stream and the amygdala just after lexical 
access. Such an early enhancement of sensory responses by the amygdala might be critical for eliciting adaptive allocation of processing resources based on affective values (Anderson \& Phelps, 2001), such as, for example, the appraisal of verbal emotion.

Interestingly, when reading emotional words in L2 the EPN was similar in magnitude but delayed compared to L1 word reading. This suggests that these words in L2 are equally attended to, but the conceptual identification of a visual word form takes longer. Such a protracted lexical access for bilinguals has been previously demonstrated for Dutch/English bilinguals using a language-specific lexical decision task (Duyck et al., 2008). Participants in this study responded significantly slower to correct words in L2 (English) as compared to words in their L1 (Dutch) but also as compared to monolingual speakers of English. Similarly, longer response times were observed for English-Spanish bilingual speakers as compared to English monolingual speakers in a semantic fluency task (Sandoval et al., 2010). Further evidence for delayed lexical access in bilinguals stems from studies using picture naming tasks both in L1 and L2 (Gollan et al., 2008, 2005, see Hanulová et al., 2011 for review). These studies consistently report a bilingual disadvantage for naming, with proficient bilingual participants naming pictures significantly more slowly in their non dominant language (either L1 or L2 Gollan et al., 2005) as compared to monolinguals. In one study, slower naming has been demonstrated even for the first/dominant language of the bilingual speakers when compared with monolingual speakers (Ivanova \& Costa, 2008). These results were explained in terms of interference 
between the two languages (Kroll et al., 2006; Sandoval et al., 2010). More specifically it was assumed that interference is greater in the non-dominant language (usually L2) than it is for the dominant language language (usually L1). In a similar vein post lexical semantic processing as reflected in the N400 event-related response investigated in the semantic violation paradigm was shown to be delayed in bilinguals compared to monolinguals, as well as in bilinguals reading in their L2 relative to L1 language (Hahne, 2001; Hahne \& Friederici, 2001; Moreno \& Kutas, 2005; Weber-Fox \& Neville, 1996, see Moreno et al., 2008 for review). According to the proposal outlined above, that the enhanced processing of emotional words occurs after a word's representation in the mental lexicon has been accessed, one could argue that the delayed processing of a word's emotionality in L2 arose from the lagged lexical access. This delayed activation might also explain previous results showing comparable SCR for L1 and L2 taboo words for high proficient L2 users (e.g., Harris, 2004). Given that the interstimulus interval is usually long when SCR data is collected, the present data suggest that under these circumstances the participants had sufficient time to access the mental lexicon and, as a consequence, to invoke each word's emotional context.

What appears to be counterintuitive to the above proposal is the present observation of a decelerated lexical access with better task performance. It should be noted, however, that neither age of L2 acquisition, nor frequency of recent L2 use nor self-rated proficiency in L2 comprehension, reading and writing abilities did predict the temporal delay 
of the EPN. As the lexical decision task is a very common task used to investigate lexical access this might indicate that it is specifically a delayed lexical access rather than other variables known to influence L2 proficiency in sequential bilingual speakers that might account for the later occurrence of the EPN effect in L2. This view is in line with current models of the organization of the bilingual lexicon (Dijkstra, 2005; Kroll \& Tokowicz, 2005; Thomas \& Van Heuven, 2005). These models claim that the mental lexicon in L2 users becomes more integrated across the L1 and L2 as proficiency develops. As an example, Van Hell and Dijkstra (2002) reported shorter lexical decision times to L1 words (Dutch) that were cognates with their L2 translations (English or French) as compared to noncognates. This effect, however, was restricted to the L1 cognates of the high proficient L2 (English). These results led to the conclusion that in highly proficient L2 speakers the presentation of a word in one language automatically activates the mental representation of corresponding words from L1 and L2 in parallel, implying a profoundly nonselective language processing system in high proficient bilinguals (Kroll et al., 2005; Van Hell \& Dijkstra, 2002). In other words, the greater an individual's proficiency in the L2, the more integrated seems the mental lexicon across languages (see Dong et al., 2005, for a similar argument). This integration may underlie the unexpected association between better task performance in L2 and delayed EPN effects in emotional word processing. Thus, when a valenced word is encountered in L2, both lexical representations are activated. This in turn causes higher interference between L1 and L2 when both lexicons are highly 
integrated than when they are much less integrated, leading to a delayed lexical access and longer latencies of the EPN effect in L2. In support of this view it has been shown that less efficient general L2 lexical access as indicated by highly varying reaction times in an animacy judgment task was associated with more automatic processing of the affective word stimuli in the Implicit Affect Association Task (i.e., a greater incongruency effect, Segalowitz et al., 2008). Moreover, a recent ERP study on professional simultaneous interpreters (Proverbio et al., 2004) showed a relationship between the number of languages proficiently mastered by these professionals and the response speed to both L1 and L2 words in a semantic decision-making task. Crucially, the higher the number of spoken languages (up to eight) and, as a consequence, the larger the overall vocabulary, the slower the lexical processing. Assuming that such cross-linguistic effects will generally be larger from L1 to L2 than in the opposite direction (Dijkstra \& van Heuven, 2002), and given that our participants were unbalanced bilingual speakers with a dominant L1, it is conceivable that the observed temporal delay of lexical access is more pronounced in the respective $\mathrm{L} 2$.

Taken together, our results provide some new insights into the way emotional valence of words in L2 is processed. Crucially, they suggest that the lexical access to emotional words in high proficient L2 users is delayed due to higher costs of interference resolution in an integrated L1-L2 lexicon. Thus, the access to a word's emotional context is not fully automatic but rather requires some additional processing resources (Hinojosa et al., 
2010). As a consequence, experiencing a word's emotionality in L2 is diminished. This might be of special importance for the natural everyday communication process, as the rapid succession of words in an utterance might hinder the resource demanding access to a word's emotional status. Thus, sensing emotional connotations in L2 might be flattened as it would need some more processing time which would not be necessarily available in a natural conversation. Contrasting real life situations, laboratory settings such as ours rely on isolated words or short phrases, thus giving enough time for lexical access and the subsequent (delayed) appraisal of the verbal emotion. Future research on emotional processing in L2 should thus try to implement studies using more natural stimulus material such as full sentences or auditory speech.

Acknowledgements: We thank Philippe Ginsbourger for help with data collection and Dr. Rahul Premraj for valuable comments on an earlier version of this manuscript. 


\section{References}

Altarriba, J. (2003). Does cariño equal liking? A theoretical approach to conceptual nonequivalence between languages. International Journal of Bilingualism, 7, 305$-322$

Altarriba, J., \& Canary, T. M. (2004). The Influence of Emotional Arousal on Affective Priming in Monolingual and Bilingual Speakers. Journal of Multilingual and Multicultural Development, 25, 248-265.

Anderson, A. K., \& Phelps, E. A. (2001). Lesions of the human amygdala impair enhanced perception of emotionally salient events. Nature, 411, 305-309.

Anooshian, L., \& Hertel, P. (1994). Emotionality in free speech: Specificity in bilingual memory. Cognition and Emotion, 8, 503-514.

Baayen, R., Piepenbrock, R., \& Gulikers, L. (1995). The CELEX Lexical Database (CDROM). University of Pennsylvania. PA.

Bayer, M., Sommer, W., \& Schacht, A. (2010). Reading emotional words within sentences: the impact of arousal and valence on event-related potentials. International Journal of Psychophysiology, 78, 299-307.

Bond, M., \& Lai, T.-M. (1986). Embarrassment and code-switching into a second language. Journal of Social Psychology, 126, 179-186.

Bradley, M. M., \& Lang, P. J. (1994). Measuring emotion: The self-assessment manikin and the semantic differential. Journal of Behavior Therapy and Experimental Psychiatry, 25, 49-59.

Costa, A., Caramazza, A., \& Sebastian-Galles, N. (2000). The cognate facilitation effect: implications for models of lexical access. Journal of Experimental Psychology Learning Memory and Cognition, 26, 1283-1296.

Degner, J., Doycheva, C., \& Wentura, D. (2012). It matters how much you talk: On the automaticity of affective connotations of first and second language words. Bilingualism: Language and Cognition, 15, 181-189. 
Dewaele, J.-M. (2004). The emotional force of swearwords and taboo words in the speech of multilinguals. Journal of Multicultural and Multilingual Development, 25, 204-222.

Dijkstra, T. (2005). Bilingual visual word recognition and lexical access. In J. F. Kroll, \& A. De Groot (Eds.), Handbook of Bilingualism Psycholinguistic Approaches chapter 9. (pp. 179-201). Oxford, UK: Oxford University Press volume 54.

Dijkstra, T., \& van Heuven, W. J. (2002). The architecture of the bilingual word recognition system: From identification to decision. Bilingualism: Language and Cognition, $5,175-197$.

Dong, Y., Gui, S., \& Macwhinney, B. (2005). Shared and separate meanings in the bilingual mental lexicon. Bilingualism, 8, 221.

Duyck, W., Vanderelst, D., Desmet, T., \& Hartsuiker, R. J. (2008). The frequency effect in second-language visual word recognition. Psychonomic Bulletin \& Review, 15, 850855.

Gollan, T. H., Montoya, R. I., Cera, C., \& Sandoval, T. C. (2008). More use almost always a means a smaller frequency effect: Aging, bilingualism, and the weaker links hypothesis. Journal of Memory \& Language, 58, 787-814.

Gollan, T. H., Montoya, R. I., Fennema-Notestine, C., \& Morris, S. K. (2005). Bilingualism affects picture naming but not picture classification. Memory \& Cognition, 33, $1220-1234$.

Gratton, G., Coles, M. G. H., \& Donchin, E. (1983). A new method for off-line removal of ocular artifact. Electroencephalogr Clin Neurophysiol, 55, 468-484.

Hahne, A. (2001). What's different in second-language processing? Evidence from eventrelated brain potentials. J Psycholinguist Res., 30, 251-266.

Hahne, A., \& Friederici, A. D. (2001). Processing a second language: late learners' comprehension mechanisms as revealed by event-related brain potentials. Bilingualism: Language and Cognition, 4, 123-141. 
Hanulová, J., Davidson, D. J., \& Indefrey, P. (2011). Where does the delay in L2 picture naming come from? Psycholinguistic and neurocognitive evidence on second language word production. Language and Cognitive Processes, 27, 902-934.

Harris, C. L. (2004). Bilingual speakers in the lab: Psychophysiological measures of emotional reactivity. Journal of Multicultural and Multilingual Development, 25, 223-247.

Harris, C. L., Ayçiçegi, A., \& Gleason, J. B. (2003). Taboo words and reprimands elicit greater autonomic reactivity in a first language than in a second language. Applied Psycholinguistics, 24, 561-579.

Harris, C. L., Gleason, J. B., \& Ayçiçegi, A. (2006). When is a first language more emotional? Psychophysiological evidence from bilingual speakers. In A. Pavlenko (Ed.), Bilingual minds: Emotional experience, expression, and representation (pp. 257-283). Clevedon, UK: Multilingual Matters.

Herbert, C., Junghöfer, M., \& Kissler, J. (2008). Event related potentials to emotional adjectives during reading. Psychophysiology, 45, 487-498.

Hinojosa, J. a., Méndez-Bértolo, C., \& Pozo, M. a. (2010). Looking at emotional words is not the same as reading emotional words: Behavioral and neural correlates. Psychophysiology, 47, 748-57.

Ivanova, I., \& Costa, A. (2008). Does bilingualism hamper lexical access in speech production? Acta Psychologica, 127, 277-88.

Kissler, J., Herbert, C., Peyk, P., \& Junghöfer, M. (2007). Buzzwords: early cortical responses to emotional words during reading. Psychological Science, 18, 475-80.

Kissler, J., Herbert, C., Winkler, I., \& Junghöfer, M. (2009). Emotion and attention in visual word processing: an ERP study. Biological Psychology, 80, 75-83.

Kroll, J., \& Tokowicz, N. (2005). Models of bilingual representation and processing. In J. F. Kroll, \& A. De Groot (Eds.), Handbook of Bilingualism Psycholinguistic Approaches (pp. 531 - 553). Oxford, UK: Oxford University Press. 
Kroll, J. F., Bobb, S. C., \& Wodniecka, Z. (2006). Language selectivity is the exception, not the rule: Arguments against a fixed locus of language selection in bilingual speech. Bilingualism: Language and Cognition, 9, 119.

Kroll, J. F., Sumutka, B. M., \& Schwartz, a. I. (2005). A cognitive view of the bilingual lexicon: Reading and speaking words in two languages. International Journal of Bilingualism, 9, 27-48.

Lang, P. J., Bradley, M. M., \& Cuthbert, B. N. (1997). Motivated attention: affect, activation, and action. In P. J. Lang, R. F. Simons, \& M. Balaban (Eds.), Attention and Emotion: Sensory and Motivational Processes (pp. 97-135). Mahwah, NJ: Erlbaum.

Moreno, E. M., \& Kutas, M. (2005). Processing semantic anomalies in two languages: an electrophysiological exploration in both languages of Spanish-English bilinguals. Brain research. Cognitive brain research, 22, 205-20.

Moreno, E. M., Rodríguez-Fornells, A., \& Laine, M. (2008). Event-related potentials (ERPs) in the study of bilingual language processing. Journal of Neurolinguistics, 21, 477-508.

New, B., Pallier, C., Brysbaert, M., \& Ferrand, L. (2004). Lexique 2: a new French lexical database. Behavior research methods, instruments, \& computers : a journal of the Psychonomic Society, Inc, 36, 516-24.

Palazova, M., Mantwill, K., Sommer, W., \& Schacht, A. (2011). Are effects of emotion in single words non-lexical? Evidence from event-related brain potentials. Neuropsychologia, 49, 2766-75.

Pavlenko, A. (2005). Emotions and Bilingualism. New York: Cambridge University Press.

Pavlenko, A. (2008). Emotion and emotion-laden words in the bilingual lexicon. Bilingualism: Language and Cognition, 11, 147-164.

Proverbio, A. M., Leoni, G., \& Zani, A. (2004). Language switching mechanisms in simultaneous interpreters: an ERP study. Neuropsychologia, 42, 1636-56. 
Sandoval, T. C., Gollan, T. H., Ferreira, V. S., \& Salmon, D. P. (2010). What causes the bilingual disadvantage in verbal fluency? The dual-task analogy. Bilingualism: Language and Cognition, 13, 231.

Schacht, A., \& Sommer, W. (2009a). Emotions in word and face processing: early and late cortical responses. Brain and Cognition, 69, 538-50.

Schacht, A., \& Sommer, W. (2009b). Time course and task dependence of emotion effects in word processing. Cognitive, Affective \& Behavioral Neuroscience, 9, 28-43.

Schupp, H. T., Junghöfer, M., Weike, A. I., \& Hamm, A. O. (2003). Attention and emotion: an ERP analysis of facilitated emotional stimulus processing. Neuroreport, $14,1107-10$.

Schupp, H. T., Stockburger, J., Bublatzky, F., Junghöfer, M., Weike, A. I., \& Hamm, A. O. (2007a). Explicit attention interferes with selective emotion processing in human extrastriate cortex. BMC Neuroscience, 8, 16.

Schupp, H. T., Stockburger, J., Codispoti, M., Junghöfer, M., Weike, A. I., \& Hamm, A. O. (2007b). Selective visual attention to emotion. The Journal of Neuroscience, 27, 1082-9.

Scott, G. G., O’Donnell, P. J., Leuthold, H., \& Sereno, S. C. (2009). Early emotion word processing: evidence from event-related potentials. Biological psychology, 80, 95-104.

Segalowitz, N., Trofimovich, P., Gatbonton, E., \& Sokolovskaya, A. (2008). Feeling affect in a second language: The role of word recognition automaticity. The Mental Lexicon, 3, 47-71.

Sharbrough, F., Chatrian, G., Lesser, R. P., Lüders, H., Nuwer, M., \& Picton, T. W. (1991). American Electroencephalographic Society Guidelines for Standard Electrode Position Nomenclature volume 8. American EEG Society.

Thomas, M. S. C. \& Van Heuven, W. J. B. (2005). Computational Models of Bilingual Comprehension. In J. F. Kroll, \& A. M. B. De Groot (Eds.), Handbook of Bilingualism 
Psycholinguistic Approaches chapter 10. (pp. 202-225). Oxford, New York: Oxford University Press.

Van Hell, J. G., \& Dijkstra, T. (2002). Foreign language knowledge can influence native language performance in exclusively native contexts. Psychonomic B, 9, 780-789.

Vuilleumier, P., Richardson, M. P., Armony, J. L., Driver, J., \& Dolan, R. J. (2004). Distant influences of amygdala lesion on visual cortical activation during emotional face processing. Nature Neuroscience, 7, 1271-8.

Weber-Fox, C. M., \& Neville, H. (1996). Maturational constraints on functional specializations for language processing: ERP and behavioral evidence in bilingual speakers. $J$ Cogn Neurosci, 8, 231-256. 
Table 1: Characteristics of the word stimuli used in the experiment [Mean and (SD)]

\begin{tabular}{ccc|cc|cc|cc}
\hline \hline & \multicolumn{2}{c}{ Arousal } & \multicolumn{2}{c}{ Valence } & \multicolumn{2}{c}{ Word length } & \multicolumn{2}{c}{ Word frequency } \\
& French & German & French & German & French & German & French & German \\
\hline \multirow{2}{*}{ Positive } & 5.32 & 5.04 & 6.97 & 7.02 & 7.33 & 7.68 & 84.13 & 76.09 \\
& $(0.88)$ & $(0.95)$ & $(0.45)$ & $(0.46)$ & $(2.51)$ & $(2.70)$ & $(142.88)$ & $(123.35)$ \\
& & & & & & & & \\
Neutral & $(0.24$ & 4.18 & 5.32 & 5.34 & 5.82 & 5.63 & 104.40 & 101.12 \\
& $(0.66)$ & $(0.38)$ & $(0.36)$ & $(1.58)$ & $(1.85)$ & $(179.22)$ & $(208.35)$ \\
& 6.22 & 6.26 & 2.99 & 2.96 & 7.32 & 7.59 & 48.67 & 33.14 \\
Negative & $(0.87)$ & $(1.01)$ & $(0.61)$ & $(0.60)$ & $(2.31)$ & $(2.65)$ & $(95.54)$ & $(84.97)$ \\
& & & & & & & & \\
\hline \hline
\end{tabular}

Note: Word frequency (absolute) is based on counts per million for written German from the CELEX database (Baayen et al., 1995) and for French from the LEXIQUE database (New et al., 2004), respectively. 
Table 2: Proportion hits to pseudo-words in the LDT.

\begin{tabular}{lcc}
\hline \hline \multirow{2}{*}{ Native Language } & \multicolumn{2}{c}{ proportion hits $( \pm$ SEM) } \\
& L1 & L2 \\
\hline German & $.94(.03)$ & $.72(.05)$ \\
French & $.91(.02)$ & $.68(.05)$ \\
\hline \hline
\end{tabular}


Table 3: Correlations between the EPN delay in L2, task performance age of L2 acquisition and selfratings of L2-proficiency and frequency of use.

\begin{tabular}{l|ccccc}
\hline \hline & 1 & 2 & 3 & 4 & 5 \\
\hline 1. EPN delay & - & & & & \\
2. age of acquisition & -.19 & - & & & \\
3. frequency of use & .17 & -.01 & - & & \\
4. self-reported proficiency & $.31^{*}$ & .01 & -.22 & - & \\
5. accuracy in the L2-LMT & $.57^{* *}$ & -.15 & -.03 & $.53^{* *}$ & - \\
\hline \hline
\end{tabular}

${ }^{*}-p<.05,{ }^{* *}-p<.001$ 
Table 4: Results of a stepwise regression analysis with EPN delay as the dependent variable.

\begin{tabular}{lccc}
\hline \hline & $\beta$ & $\mathrm{T}$ & $\mathrm{p}$ \\
\hline included variables & & & \\
accuracy in the L2-LMT & .566 & 3.71 & .001 \\
& & & \\
excluded variables & & & \\
age of acquisition & -.107 & -.68 & .500 \\
frequency of use & .155 & 1.01 & .319 \\
self-reported proficiency & .020 & .109 & .914 \\
accuracy in the L1-LMT & -.099 & -.528 & .601 \\
\hline \hline
\end{tabular}




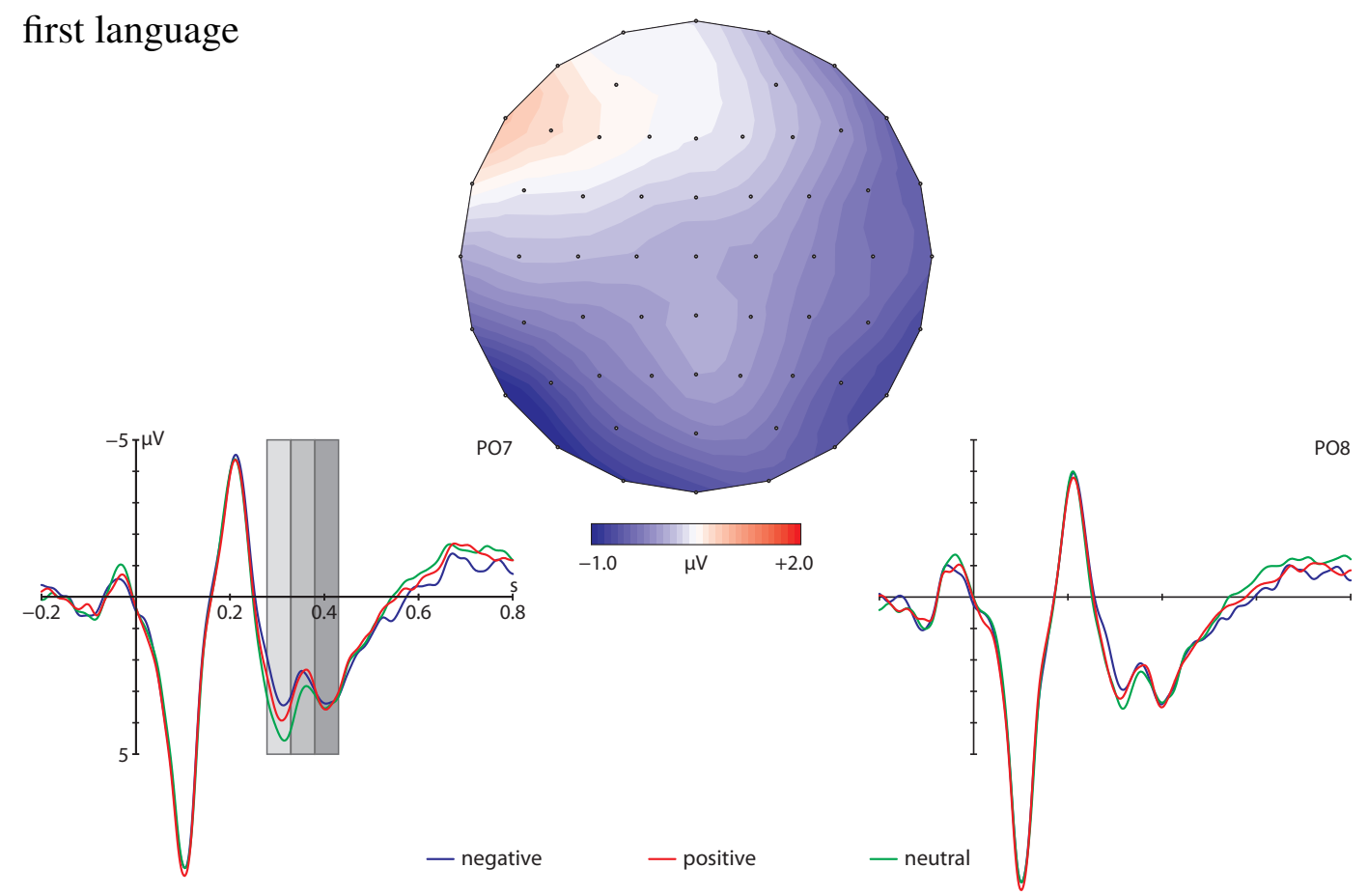

second language
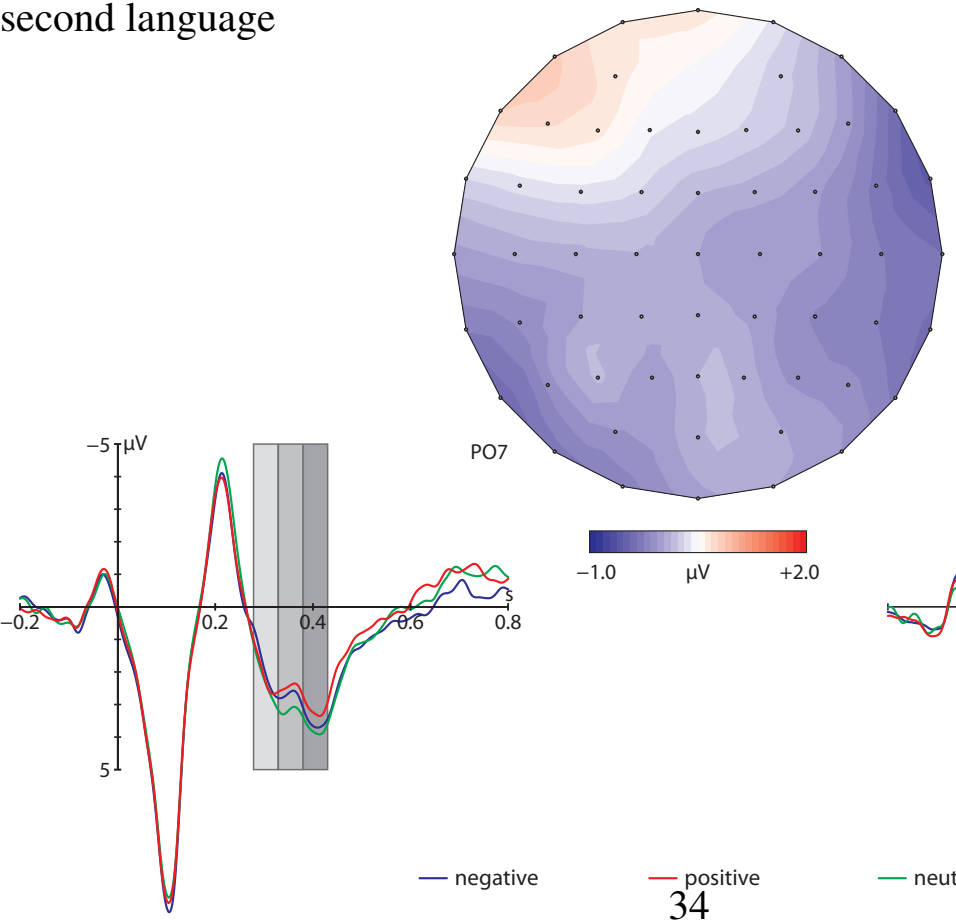

$\mathrm{OO}$

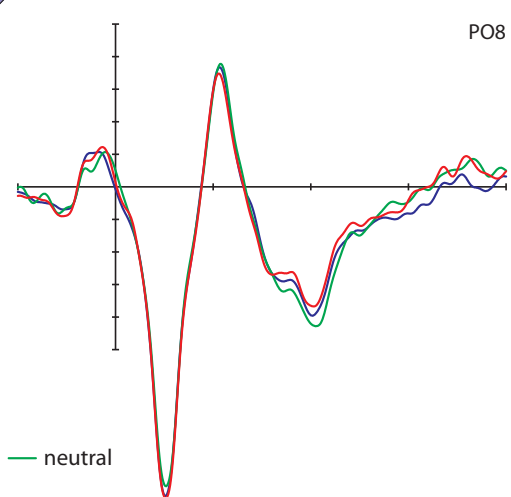

Figure 1: Effects of word valence in L1 (top) and L2 (bottom) processing. ERP waveforms from two temporo-occipital channels in both hemispheres are shown separately for pleasant, unpleasant and neutral words. The three gray bars indicate the successive time windows used for statistical analysis. The topography map depicts the difference of cortical responses to emotional minus neutral words in the $280-380 \mathrm{~ms}$ time interval after word onset. As there was no interaction involving pleasantness the topographical view collapses across pleasant and unpleasant words. 